\title{
Do Personal Attributes and An Understanding of Sarcasm and Metaphor Explain Problematic Experiences on the Internet? \\ -A Survey for the Development of Information Literacy Education Tools-
}

\author{
${ }^{1}$ Yuhiko Toyoda, ${ }^{2}$ Mika Takeuchi, ${ }^{3}$ Hiroshi Ichikawa, ${ }^{4}$ Mitsuteru Tashiro and ${ }^{5}$ Masao Suzuki \\ ${ }^{1}$ School of Business administration, Sanno University, Japan; \\ ${ }^{2}$ Department of Humanities and Social Sciences, Jissen Women's University, Japan; \\ ${ }^{3}$ Department of Home Economics, Otsuma Women's University, Japan; \\ ${ }^{4}$ Institute for InfoSocionomics, Tama University, Japan; \\ ${ }^{5}$ Department of Human Sciences, Waseda University, Japan; \\ toyoda_yuhiko@hj.sanno.ac.jp; takeuchi-mika@jissen.ac.jp; ichikawa.h@otsuma.ac.jp; \\ tashiro@ni.tama.ac.jp; masaosuz@waseda.jp
}

\begin{abstract}
The Internet today provides users with a great amount of convenience due to the improvement of tools and their functions, and the expansion in the numbers of users. However, with the expansion of both online content and time spent online, new and potential risks have emerged in this virtual space. A majority of Japanese students experience communication troubles over the Internet, and therefore higher education institutions have increased their efforts to reduce risks on the Internet by, for example, offering basic security education through information literacy programs. However, because of the number and variability of Internet risks, it is unlikely that these efforts have achieved satisfactory results. As one of the risk factors inducing troubles on the Internet, where users exchange information with other (anonymous) users, we examine the immaturity of the "theory of mind," which is generally used to infer the conditions, viewpoints, and comprehension level of others.
\end{abstract}

This study reports the results of a self-report questionnaire used to examine the problems or difficulties encountered on the Internet by young women in Japan. It focuses on the relationship between the comprehension of sarcasm and metaphor expressions, provided for the purpose of estimating the "theory of mind," as well as of Internet terminology and the problematic experiences. The problems identified were roughly classified into four different categories: addictive Internet use, dishonest/illegal dealings, communication gaps, and shopping-related difficulties. Multiple regression analyses was conducted, aimed at identifying factors that could explain such problems. The results suggested that personal attributes and sensation-seeking tendencies, including social vulnerability and anxiety, and the understanding of sarcasm, metaphor expressions, and Internet terminology, might be significantly correlated with the problems experienced. On the basis of this study, proposals are made as to what areas should be focused on in information literacy education programs in the future.

Keywords: Internet Risk, comprehension of metaphor and sarcasm, theory of mind, educational tool 
Yuhiko Toyoda, Mika Takeuchi, Hiroshi Ichikawa, Mitsuteru Tashiro, Masao Suzuki; Do Personal Attributes and An Understanding of Sarcasm and Metaphor Explain Problematic Experiences on the Internet? -A Survey for the Development of Information Literacy Education Tools-, Transactions on Networks and Communications, Volume 3 No 2, April (2015); pp: 159-177

\section{Introduction}

As the Internet has become more ubiquitous in both private and public life, the access to information has drastically improved. However, at the same time the risks related to Internet use have also grown. With these growing risks in mind, the Organization for Economic Co-operation and Development (OECD) published a recommendation in 2012 on the risk of Internet use by adolescents, entitled "The Protection of Children Online[1]. Recommendation of the OECD Council, Report on risks faced by children online and policies to protect them." Following these OECD recommendations, Japan's Ministry of Internal Affairs and Communications published a summary report on the Internet Literacy Assessment indicator for Students (ILAS)[2]. This report found that children who had received Internet security education or had discussed it with their family were much more aware of the security concerns. In line with efforts to increase awareness, this study presents the results of a survey on female students' personal attributes and their understanding of sarcasm, metaphor, and Internet terminology-all of which were speculated to be related to difficulties experienced on the Internet-and also examines the predictability of these factors.

\section{Background and Literature Review}

Electronic communication media such as Twitter, Facebook, and Line are extensively used in Japan, especially by adolescents. When using these communication methods, although it is easy to transmit messages, a simple error or a poorly chosen comment may lead to difficulties. For example, in recent years, a convenience store was forced to close because one of its employees posted a photo of himself lying in a freezer to provide a topic of conversation for his friends. In another incident, a student posted a photo of a stranger online accompanied with a defamatory comment about the stranger; as a result his university was flooded with complaint calls and he was eventually forced to drop out of school.

\subsection{The difference between "Enjoh" and "Flaming"}

Hirai [3] found that the origin of the so-called "enjoh" (a Japanese term literally meaning "fire spreading") was an incident on a blog where abusive and slanderous comments were made about a comment posted by an ordinary user, and then examined several similar, widespread cases. Hirai cited Thurlow et al., [4] to differentiate between "flaming" and "enjoh." In his study, flaming was defined as a "hostile and aggressive mutual act in computer-mediated communication (Thurlow et al., ). "Enjoh" in Japan is defined by Hirai [3] as a "phenomenon in which a message contributed to such services as blogs, mixi or Twitter, as well as the person who posted such a message, [is] flooded with criticism and blame." Interestingly, "at first, 'enjoh' referred to only some of the events or topics in the electronic forum named '2channel'." O'Sullivan and Flanigan [5] described "enjoh" and "flaming" as separate phenomena by examining the differences in those involved, saying "even if there is an exchange of words which seem to be denouncing (others) online, the norm of the mutual act is not violated and such a case will not be considered flaming, which is a hostile and aggressive mutual act, in case those who exchange messages recognize that what they are doing is a 'word game' or a 'joke'."

Twitter is a highly representative cyber-community in which specific users participate. The characteristics of the user communities have been described in a number of studies (Takeichi \& Sasahara et al., [6]; Kwak et al., [7]; Bollen et al., [8]; Grabowicz et al., [9]; Conover et al., [10]). Highly particular network structures between users (Kwak et al., [7]; Bollen et al., [2]), particularity in 
the nature of social negotiation (Grabowicz et al., [9]; Conover et al., [10]), information diffusion (Romero et al., [11]; Weng et al., [12]), collective attention (Lehmann et al., [13]), collective mood (Golder and Macy, [14]), and user dynamics related to particular real-life events (Sakaki et al., [15]; Borge-Holthoefer et al., [16]; Gonz'alez-Bail'on et al., [17]) have all been examined. Twitter, as a simultaneous communication medium, is used by a community of users to search for events and topics that are happening now (Takahashi et al., [18]), and is even referred to for trend searches in the stock markets (Bollen et al., [19]). It has been described as a "social sensor" (Takeichi \& Sasahara et al., [6]). The Great Eastern Japan Earthquake drew attention to the intricate functions of Twitter, and the use of the service to search for chronological traces or "digital fossils," by looking for events that received collective attention and collective responses, was examined in detail (Sasahara, K., Hirata, Y., Toyoda, M., Kitsuregawa, M. \& Aihara, K., [20]).

The boundary between "enjoh" and "flaming" becomes more ambiguous as the online community, which once consisted of sensible "experts" who were able to distinguish between "jokes among friends" and serious violations of fundamental human rights, grows to include all people in society.

Because anybody can easily participate in cyber space anonymously, the ambivalence of the vulnerability caused by a lack of strong protection of personal information remains unresolved.

\subsection{Human errors, "problems" and "potential problems" in cyber communication}

Serious social problems are often caused by releasing information without understanding the nature of the Internet. Many senders of problematic messages are often not interested in the security of their own personal information, and the information left in their SNS accounts or blogs is readily searched for and collected. It is not rare for the name of their school and their residential address to be disclosed on the web. As a result, some institutions have had their operations hindered or suspended, and there have been tragic cases of individuals forced to quit their schools or jobs.

Heinrich's law states that behind great accidents there are smaller cases in the preparatory stage. Heinrich [21], the father of the safety study, was the first to introduce the rule of thumb according to which "if a major accident occurs, 29 medium-scale accidents have occurred in the surroundings and 300 small-scale accidents behind." For major incidents related to Internet communication, in reference to this general principle of accident potency, it is likely that the number of problems that actually occur is much more than the number of cases recognized as problems. In information literacy education, it may therefore be necessary to exclude estimations based on wishful thinking as to the number of "potential problems."

The "error of prediction" refers to human errors that cause accidents. Errors of prediction occur in cyber space as a result of the action selected by a transmitter who does not sufficiently predict public reaction to the information or who remains incapable of careful estimation. To prevent errors, it is essential to improve the precision of the predicted result of the action; that is, to collect accurate information in advance so as to make adaptive choices.

One of the features of cyber space communication is that the information sender and receiver do not share a time and space face-to-face, and that the participants are not necessarily specified. This makes it difficult to perform the basic safety measures of prediction and control. In face-to-face communication, it is expected that a person's point of view is different from others and that there is a gap in the quality and quantity of information a person has, which means that it is not easy for two or more people to arrive at a mutually sufficient level of "comprehension" and satisfaction. The most central tasks for human social development include being able to reach a common viewpoint (by 
Yuhiko Toyoda, Mika Takeuchi, Hiroshi Ichikawa, Mitsuteru Tashiro, Masao Suzuki; Do Personal Attributes and An Understanding of Sarcasm and Metaphor Explain Problematic Experiences on the Internet? -A Survey for the Development of Information Literacy Education Tools-, Transactions on Networks and Communications, Volume 3 No 2, April (2015); pp: 159-177

trial and error) that encompasses the differences between two people, and the process of learning the skills needed to coordinate with others. Cyber communication imposes a learning task on users that is more difficult to solve than a task related to direct communication.

\subsection{Possibility of applying the "theory of mind" to cyber communication}

The "theory of mind" is the overall process of estimating other people's viewpoints (by abandoning one's own), adequately identifying the difference between the information used by others and the information belonging to oneself, and then coordinating and selecting one's own behavior. Studies on the "theory of mind" encompass ethology, pedagogy, cognitive science, psychology and clinical developmental psychology, especially in the field of the rehabilitation of children and adolescents with pervasive developmental orders (PDD, especially Asperger's Syndrome or autism spectrum disorders) according to the needs and interests in each field. Research in this area was first conducted by Premack \& Woodruff [22], who observed the behavior of primates such as chimpanzees. Premack [23] considered that if animals or human beings could understand what they themselves or others intend, know, believe, think, doubt, suppose, pretend or like, then they could be regarded as having a "theory of mind."

Hobson [24] and Moore [25] stated that "a child tries to understand others as those who are similar to him/herself in that they are sources of subjective attitudes but sometimes have a mental attitude that is different from his/hers, as individual beings that have peculiar attitudes and viewpoints." Hobson and Moore believed that children formed the basic framework for an understanding of the "self and others" when they went through such a process. Baron-Cohen et al [26] considered it an important goal of the "theory of mind" to differentiate between those who have a correct belief by themselves and noticing those who have a wrong belief, and examined the developmental process using a false-belief task.

The "Sally-Anne Test" is typical of a false-belief task. This task consists of asking participants (children) where Sally (an "other" or distinct person), whose doll has been moved somewhere else by someone (Anne) during Sally's absence, could look for the doll. In this task, the "theory of mind" is necessary for participants to able to notice the difference between having a correct belief (i.e., they know that the doll is not at the original place) and being aware that the leading character of the story (Sally) has an incorrect belief (i.e., that the doll is in the original place). This task, also referred to as an "unexpected task," requires participants to abandon their own beliefs and viewpoints and to put themselves in the position of others.

There have been debates as to the point in the developmental stage at which this psychological process commences or is achieved. Research on this theme has developed along various paths, and has been included in brain function development trials. In recent years, functional neuroimaging studies have been actively conducted using fMRI (function MRI) (for example, see Takamiya, Matsui, Kobayashi et al, [27] and Moriguchi, [28]). During the execution of a "theory of mind" task with normal adolescents, when the task was accomplished, an activation of the medial and lateral prefrontal cortexes and the orbito-frontal cortex was observed. A study on the personality attributes related to psychosomatic disorders indicated that alexithymia (difficulty in identifying and describing emotions in the self) was characterized by self-emotional disturbances which included difficulty in realizing a person's sentiments in the act of representation. Moriguchi reported that changes in the 
function of the medial prefrontal cortex had been observed, which helped to represent a person's own mind and an understanding of others.

Adachi et al., [29] conducted an experiment aimed at investigating the situation recognition skills and related particularities of participants with attention deficit/hyperactivity disorder (AD/HD), Asperger's Syndrome (AS) or pervasive developmental disorders including high functioning autism, using a metaphor and sarcasm scenario test (MSST). It was found that participants with AS had difficulty understanding sarcasm even though their language ability was good, while there was no difference between the scores for metaphor and sarcasm in the group with high functioning autism (HFA) and groups with AD/HD. Adachi (2006) pointed out that "sarcasm contains negative meanings that are contrary to the wording, such as blame and ridicule. Sarcasm is valid only when it has been agreed between the speaker and the receiver of the sarcasm that what is said is contrary to the truth. That is to say, the ability to understand the implied meaning is based on judgment abilities which are different in quality for metaphoric sentences and sarcastic sentences, namely a judgment of the fact for the former and judgment of the value for the latter." It was found that the value judgment ability necessary to share sarcasm was less dependent on language ability than the ability to share metaphorical sentences, as the understanding of sarcasm does not depend on age and language ability while the understanding of metaphor does.

The "theory of mind" includes a meta-representation of oneself and others. A series of "unexpected tasks" and "sarcasm-understanding tasks," which have been developed as functional development and achievement in human socialization indexes, contain stories with unusual settings. The tasks can be enlarged to include daily scenes, so that the execution level can be estimated. Participants are required to depart from their own linear beliefs and viewpoints to carry out a meta-representation task which consists of readily moving those representations onto others.

Today, young people spend a great deal of their life interacting in cyber space. It is necessary to examine how these young people, who are living daily examples of "enjoh," "flaming," or fraud, can build meta-representations in their relationships with themselves and others in cyber space. Communication in cyber space has unknown processes that are still considered to be in the experimental stage. It may be possible that there are incidents that have been caused by an incomplete "theory of mind" in terms of the "problems" that have occurred and the "potential problems" that could occur. This speculation suggests that the content of current information literacy education needs to be re-examined and expanded.

This study examines the results of a self-report questionnaire completed by university students to obtain basic data on their experience of "problems" and "potential problems" in their use of cyber space, as well as on the personal attributes related to such experiences and the achievement of the "theory of mind."

\section{Methods}

\subsection{Participants}

The survey was conducted on 454 female students studying at a junior college at two women's universities in Tokyo prefecture, using a self-report format.

These respondents were all attending a commuting course, in which the researchers are responsible for information literacy education. Respondents agreed on the significance and necessity of the epidemiological research, having fully understood the necessity of information literacy through lectures at the university. This survey was conducted with educational urgency, as it was felt that 
Yuhiko Toyoda, Mika Takeuchi, Hiroshi Ichikawa, Mitsuteru Tashiro, Masao Suzuki; Do Personal Attributes and An Understanding of Sarcasm and Metaphor Explain Problematic Experiences on the Internet? -A Survey for the Development of Information Literacy Education Tools-, Transactions on Networks and Communications, Volume 3 No 2, April (2015); pp: 159-177

female adolescents suffer larger psychosocial, psychosomatic and mental damage than their male colleagues if they meet with accidents in cyber space. However, when the questionnaire was distributed, it was explained that participation was voluntary, that respondents could leave blank the questions they did not wish to answer, that they could stop answering questions when they wished, that they did not have to fill in their names, and that the data would be mechanically treated by a trained company with a duty of confidentiality. There is no conflict of interest in this study.

\subsection{Period of the survey}

We conducted the survey in July 2014 in a lecture room at the university. At the end of the lecture, each student was asked to respond once to the survey items on a voluntary basis.

\subsection{Research battery}

The questionnaire consisted of 60 Risk Management Test (RMT) questions developed by Takeuchi and Suzuki [30] for education against fraudulent sales, as well as questions covering the use of the Internet, problems experienced on the web, and multiple-choice interpretative questions regarding sarcasm and metaphors and knowledge of Internet terminology. The questions were organized as follows:

a. A group of questions related to the use of cyber communication, including devices used for connection and SNS sites accessed.

b. A Risk Management test (RMT): This is a self-evaluation sheet for crisis management education, and has groups of questions related to "physiological needs," "safety needs," "social belonging needs," "esteem needs," and "self-actualization needs," based on Maslow's principle of the hierarchy of needs [31]. There is also a group of questions linked to "sensation-seeking and curiosity," built on a model proposed by Cloninger [32]. The responses were given on a scale of one to five, with $1=$ "not at all" and 5 = "always."

c. Problematic experiences related to the use of the Internet (IT): Items identified in a previous study by Tashiro [33] were described and respondents were asked whether they had experienced similar cases. The responses were from $0=$ "never" to $4=$ "very often."

d. Metaphor and Sarcasm Scenario Test-for Adolescents (MSST-A) and the Internet: To test understanding of sarcasm and metaphors, we developed questions that focused on daily scenes familiar to the young respondents, with choices related to the understanding of these scenes and the related behaviors. Using the same format, we developed questions to check respondent understanding by citing examples of conversations between friends and the use of "Internet terminology."

e. Internet Terminology Questionnaires-2: The "terminology" used in cyber communication is unique. Often such specialized jargon is common only to the members of the community concerned. "Internet terminology" changes regularly and there are many terms in daily use that have originated from cyber space. As the level of knowledge and use of "Internet terminology" is expected to play a role in an index which measured the degree of cyber communication penetration in a respondents' life, we decided to identify typical "Internet terms" that are often seen 
but not so widely used in real-world conversations. In this survey, we asked respondents to answer the questions using five scales from $0=$ "I have never seen it" to $4=$ "I use it frequently."

\section{Results}

\subsection{Problems experienced on the Internet (IT)}

Only 14 out of the 452 valid responses (3.1\%) said that they had experienced "no trouble at all" related to Internet use. For the remainder, many said that these problematic experiences were related to their exposure to uncertainty, danger and unpleasant information as information receivers, such as "I have believed false rumors posted on the Internet," "I have received inviting mails/messages from strangers," and "I have received disgusting mails/messages." The experience rate for situations which indicated addictive Internet access, such as "I spend so much time on the Internet that I think I have difficulty in daily life," was also high. In addition, $46.8 \%$ of respondents indicated that they had experienced problems as senders of information, such as "I have disgusted others by mails/messages that I sent."

\subsection{Factor analysis for the problematic experiences on the Internet}

We conducted a factor analysis to examine the main patterns for problematic experiences on the Internet. Table 1 shows the result of the maximum likelihood estimation and the promax rotation. For the first factor, the factor loading for the items "I spend so much time on the Internet that I think I have difficulty in daily life," and "I spend so much time playing games that I think I have difficulty in daily life" was high, showing that this factor was related to "addiction tendency" (contribution ratio $=12.817 \%, \alpha=0.579$ ). For the second factor, items related to dishonest/illegal experiences, such as "I have posted false rumors on the Internet" and "I have accessed a computer belonging to another person before" were extracted (contribution ratio $=16.366 \%, \alpha=0.660$ ). For the third factor, communication-related items, including "I have received inviting mails/messages from strangers" and "I have received disgusting mails/messages" were extracted (contribution ratio $=12.671 \%, \alpha=$ 0.713). For the fourth factor, shopping-related items such as "Some of the articles that I ordered on Internet-order or auction services on the Internet have not arrived yet" and "Some of my requests for return have not been accepted by Internet-order or auction services" were extracted (contribution ratio $=7.676 \%, \alpha=0.736$ ). In a later analysis, we calculated the synthesized score for each factor, which was obtained by summing up the item raw scores from which the factor had been extracted.

\subsection{Factor analysis for the Risk Management Test (RMT)}

The RMT is a questionnaire sheet prepared for use in educational programs to allow students to raise their awareness by self-evaluating the risks inherent in their personal attributes that could induce fraud or solicitation (Takeuchi \& Suzuki, 2000). To examine the image structures, we conducted a factor analysis using maximum likelihood estimation and promax rotation (Table 2). When the first five factors were converted, the cumulative contribution ratio was $29.9 \%$. For the first factor, 11 items were extracted, including "I am sensitive to fashion for my clothes, hairstyle and makeup," "I adore the truth and perfect beauty and I hope to approach such things by myself," "I want to have friends and a boyfriend I can boast of to others," and "I love top-brand articles, even if they are expensive." Although the items cited for the first factor seem to be diverse at first glance, they all include items that refer to the possibility of high suggestibility, anxiety and evaluation by others. In summary, this can be understood as a factor which shows the "tendency to obey a person silently (according to an influence from an external environment)" (contribution ratio $=10.28 \%$, 
Yuhiko Toyoda, Mika Takeuchi, Hiroshi Ichikawa, Mitsuteru Tashiro, Masao Suzuki; Do Personal Attributes and An Understanding of Sarcasm and Metaphor Explain Problematic Experiences on the Internet? -A Survey for the Development of Information Literacy Education Tools-, Transactions on Networks and Communications, Volume 3 No 2, April (2015); pp: 159-177

Cronbach's $\alpha=.714)$. For the second factor, items showing "sensation-seeking," such as "I love to feel thrilled riding jet coasters and trying free falls in amusement parks" and "I want to try bungee jumping and sky diving" (contribution ratio $=7.02 \%$, Cronbach's $\alpha=.579$ ), were extracted. For the third factor, extracted items related to "anxiety over relationships," such as "I sometimes cannot say what I want for fear of hurting others" or "I tend to be unable to say no when asked to do something by others" (contribution ratio $=3.68 \%$, Cronbach's $\alpha=.641$ ). Items associated with the "desire to surpass existing regulations" such as "I hope to complete something 'original' that only I can do" and "There is something I would like to try if I were not punished by law" were extracted for the fourth factor (contribution ratio $=4.30 \%$, Cronbach's $\alpha=.390$ ). Finally, for the fifth factor, items linked to the "avoidance of physical pain," including "I want to avoid things that cause pain to my body" and "I do not want to carry out activities that put a physical burden on me" were extracted (contribution ratio $=4.03 \%$, Cronbach's $\alpha=.646)$.

Table 1: Factor analysis for problematic experiences on the Internet

\begin{tabular}{|c|c|c|c|c|}
\hline \multirow{3}{*}{ Experienced Internet Problems } & \multicolumn{4}{|c|}{ Factor Loadings } \\
\hline & $\begin{array}{l}\text { Addiction } \\
\text { tendency }\end{array}$ & $\begin{array}{c}\text { Illegality } \\
\text { experience }\end{array}$ & $\begin{array}{c}\text { Communic } \\
\text { ation }\end{array}$ & Shopping \\
\hline & factor_1 & factor_2 & factor_3 & factor_4 \\
\hline $\begin{array}{l}\text { IT12 I spend so much time on the Internet that I have difficulty in daily } \\
\text { life. }\end{array}$ & .999 & -.003 & -.001 & .000 \\
\hline $\begin{array}{l}\text { IT13 I spend so much time playing games that I have difficulty in daily } \\
\text { life. }\end{array}$ & .488 & .225 & .029 & .108 \\
\hline IT10 I have believed false rumors posted on the Internet. & .321 & .210 & .238 & -.125 \\
\hline IT09 I have posted false rumors on the Internet. & .171 & .924 & -.173 & -.074 \\
\hline $\begin{array}{l}\text { IT11 I have accessed a computer belonging to another person without } \\
\text { permission. }\end{array}$ & .124 & .562 & .075 & .072 \\
\hline $\begin{array}{l}\text { IT08 I have sent mails or made contributions to the Internet including } \\
\text { information that should be kept secret. }\end{array}$ & .274 & .533 & .051 & -.050 \\
\hline $\begin{array}{l}\text { IT04 I have received mails or messages inviting me to buy such things as } \\
\text { illegal drugs. }\end{array}$ & .103 & .382 & .321 & .218 \\
\hline IT05 I have received inviting mails/messages from strangers. & .200 & .201 & .731 & -.287 \\
\hline IT06 I have received disgusting mails/messages. & .234 & 247 & .604 & -.255 \\
\hline $\begin{array}{l}\text { IT03 I have received mails/messages claiming payment that I have } \\
\text { nothing to do with. }\end{array}$ & .165 & .222 & .574 & -.119 \\
\hline IT07 I have disgusted others by mails/messages that I sent. & .197 & .201 & .206 & .026 \\
\hline $\begin{array}{l}\text { IT01 Some of the articles that I ordered on Internet-order or auction } \\
\text { services on the Internet have not arrived yet. }\end{array}$ & .085 & .341 & .306 & .627 \\
\hline $\begin{array}{l}\text { IT02 Some of my requests for return have not been accepted by the } \\
\text { Internet-order or auction services. }\end{array}$ & .168 & .356 & .289 & .595 \\
\hline Contribution ratio(\%) & 12.817 & 16.366 & 12.671 & 7.676 \\
\hline Cumulative contribution ratio (\%) & 12.817 & 29.183 & 41.854 & 49.530 \\
\hline Cronbach's $\alpha$ & .579 & .660 & .713 & .736 \\
\hline
\end{tabular}


Table 2: Risk Management Test (RMT) factor analysis

\begin{tabular}{|c|c|c|c|c|c|}
\hline \multirow[t]{2}{*}{ Risk Management Items } & $\begin{array}{c}\text { Tendency } \\
\text { to obey a } \\
\text { person } \\
\text { silently }\end{array}$ & $\begin{array}{l}\text { Sensation } \\
\text { seeking } \\
\text { tendency }\end{array}$ & $\begin{array}{l}\text { Anxiety over } \\
\text { relationship }\end{array}$ & $\begin{array}{l}\text { Desire to } \\
\text { surpass } \\
\text { regulations }\end{array}$ & $\begin{array}{c}\text { Avoidance } \\
\text { of physical } \\
\text { pain }\end{array}$ \\
\hline & Factor 1 & Factor 2 & Factor 3 & Factor 4 & Factor 5 \\
\hline $\begin{array}{l}\text { Q39 I am sensitive to fashion for my clothes, hairstyle and } \\
\text { makeup. }\end{array}$ & .689 & .010 & -.488 & -.221 & .015 \\
\hline $\begin{array}{l}\text { Q29 I adore the truth and perfect beauty and I hope to } \\
\text { approach such things by myself. }\end{array}$ & .577 & .093 & -.049 & .081 & -.109 \\
\hline $\begin{array}{l}\text { Q28 I want to have friends and a boyfriend I can boast of } \\
\text { to others. }\end{array}$ & .521 & -.003 & .051 & .016 & -.075 \\
\hline Q16 I love top-brand articles, even if they are expensive. & .491 & .080 & -.185 & .043 & .108 \\
\hline Q03 I feel anxious when I am alone. & .405 & -.076 & .104 & .038 & .052 \\
\hline Q44 I believe in the charm or the incantation of safety. & .391 & .076 & .001 & -.075 & -.093 \\
\hline Q23 I feel attracted by pure ways of life. & .355 & -.006 & .203 & .093 & -.095 \\
\hline $\begin{array}{l}\text { Q57 I sometimes change my judgment according to } \\
\text { others' opinion. }\end{array}$ & .350 & -.134 & .273 & -.182 & .034 \\
\hline $\begin{array}{l}\text { Q37 I may be somewhat selfish in order to feel } \\
\text { comfortable. }\end{array}$ & .340 & .002 & .007 & .137 & .046 \\
\hline $\begin{array}{l}\text { Q43 I have given up something that I absolutely wanted } \\
\text { to do because of the lack of physical power. }\end{array}$ & .338 & .075 & .124 & .278 & .174 \\
\hline Q53 I want to do anything that pleases others. & .337 & .080 & .027 & .041 & -.288 \\
\hline $\begin{array}{l}\text { Q54 I love to feel thrilled riding jet coasters and trying } \\
\text { free falls in amusement parks. }\end{array}$ & .035 & .637 & .192 & -.390 & .338 \\
\hline Q48 I want to try bungee jumping and sky diving. & -.037 & .631 & .151 & -.226 & .125 \\
\hline Q18 I like dangerous things and thrilling games. & .083 & .585 & .058 & .250 & -.052 \\
\hline Q24 I am rather curious. & .215 & .385 & .003 & .175 & -.155 \\
\hline $\begin{array}{l}\text { Q60 I have intentionally tried things that I know are } \\
\text { dangerous or illegal. }\end{array}$ & .150 & .336 & .076 & .260 & .078 \\
\hline Q06 I am looking for sensations in life. & .242 & .269 & .089 & .251 & -.044 \\
\hline $\begin{array}{l}\text { Q21 I sometimes cannot say what I want for fear of } \\
\text { hurting others. }\end{array}$ & .408 & -.295 & .580 & -.242 & -.130 \\
\hline $\begin{array}{l}\text { Q33 I tend to be unable to say no when asked to do } \\
\text { something by others }\end{array}$ & .272 & -.106 & .399 & -.262 & -.179 \\
\hline $\begin{array}{l}\text { Q17 I hope to complete something "original" that only I } \\
\text { can do. }\end{array}$ & .287 & .270 & .187 & .458 & -.191 \\
\hline $\begin{array}{l}\text { Q42 There is something I would like to try if I were not } \\
\text { punished by the law. }\end{array}$ & .187 & .321 & .181 & .323 & .032 \\
\hline Q13 I want to avoid things that cause pain to my body. & .275 & -.328 & .085 & .194 & .538 \\
\hline $\begin{array}{l}\text { Q55 I do not want to carry out activities that put a } \\
\text { physical burden on me. }\end{array}$ & .131 & -.351 & .107 & .147 & .482 \\
\hline Q19 I do not have so much endurance. & .089 & -.197 & .147 & .165 & .349 \\
\hline Q01 I cannot endure "physically hard" work or tasks. & .269 & -.183 & .016 & .204 & .347 \\
\hline$\%$ of diffusion & 10.283 & 7.024 & 3.667 & 4.300 & 4.025 \\
\hline Cumulative \% & 10.283 & 17.307 & 20.973 & 25.274 & 29.299 \\
\hline Cronbach's $\alpha$ & .714 & .579 & .641 & .390 & .646 \\
\hline
\end{tabular}

For later analysis, we calculated the synthesized score for each factor, by summing up the raw scores of items from which the factor was extracted.

\subsection{Calculation of the Internet terminology comprehension score}

We asked respondents to select one out of six choices, including the answer "I do not know," to examine their comprehension of bilateral conversations where sarcasm, metaphor or Internet terminology was used. In real life scenarios, comprehension of sarcasm, metaphor and Internet terminology is in fact extensive and dependent on the context. The goal of this study was to check if those who tended to make choices that deviated from the common comprehension of the majority of dialogue participants might enter into conflicts with others in cyber space communication, where language is used as the principal medium. As there is no one correct way for the use of sarcasm and metaphor in ordinary dialogue, we calculated the MSST-A score for each respondent by extracting 
Yuhiko Toyoda, Mika Takeuchi, Hiroshi Ichikawa, Mitsuteru Tashiro, Masao Suzuki; Do Personal Attributes and An Understanding of Sarcasm and Metaphor Explain Problematic Experiences on the Internet? - A Survey for the Development of Information Literacy Education Tools-, Transactions on Networks and Communications, Volume 3 No 2, April (2015); pp: 159-177

five answers where the selection rate by respondents was between 60 and 70 percent, and then summing up the raw scores for the five questions by granting one point to those who selected the most frequent answer and zero to those who selected other answers. The MSST-A score was applied to later calculations to develop a sarcasm and metaphor comprehension index. Table 3 shows the five MSSA-related questions for the comprehension of Internet terminology.

\subsection{Multiple regression analysis using problematic Internet experiences as dependent variables}

a) Multiple regression analysis using problematic Internet experiences as the dependent variables and the RMT synthesized factor scores as independent variables:

For each of the four problematic Internet experience categories classified through the exploratory factor analysis, a multiple regression analysis was conducted using the forced entry method, so as to show the degree of explanation ratio for the RMT synthesized factor scores as personal attributes. It was found that the standardized R2 $=.074(\mathrm{Pr} .=.000)$ for the item, "addiction tendency (to the Internet) (IT_1)" was significant. Of the personal attribute variables (RMT) entered for "addiction tendency," "avoidance of physical pain: RMTscr_5" $(\beta=.193$, Pr. $=.000)$ and the "tendency to obey a person silently (according to an influence from the external environment): RMTscr_1" ( $\beta=.124$, Pr. $=.015$ ) were found to be especially significant descriptive factors. The standardized $\mathrm{R} 2=.024$ ( $\mathrm{Pr}$. = .007) for "[dishonest/]illegal experiences (IT_2)" was also shown to be significant. Of the personal attribute variables (RMT) entered for "[dishonest/] illegal experiences," "sensation seeking tendency: RMTscr_2" ( $\beta=.128$, Pr. $=.015)$ was found to be an especially significant descriptive factor. The standardized R2 =.041 (Pr. = .000) for "communication (IT_3)" was found to be significant. For the personal attribute variables (RMT) entered for "communication," "sensation seeking tendency: RMTscr_2" $(\beta=.138, \operatorname{Pr} .=.008)$ and the "desire to surpass existing regulations: RMTscr_4" ( $\beta=.013$, Pr. $=.049)$ were found to be especially significant descriptive factors. It was also found that the standardized R2 $=.028$ (Pr. = .027) for "shopping (IT_4)" was significant. For the personal attribute variables (RMT) entered for "shopping," "desire to surpass existing regulations: RMTscr_4" ( $\beta=.20$, Pr. = .016) was found to be an especially significant descriptive factor. Although these factor values are low, we can see that there are Internet usage behavior patterns that could induce problems, as the different personal attribute factors suggested significant explicability for each problematic Internet experience (see Table 4).

For later analysis, we calculated the synthesized score for each factor, by summing up the raw scores of items from which the factor was extracted.

\subsection{Calculation of the Internet Terminology Comprehension Score}

We asked respondents to select one out of six choices, including the answer "I do not know," to examine their comprehension of bilateral conversations where sarcasm, metaphor or Internet terminology was used. In real life scenarios, comprehension of sarcasm, metaphor and Internet terminology is in fact extensive and dependent on the context. The goal of this study was to check if those who tended to make choices that deviated from the common comprehension of the majority of dialogue participants might enter into conflicts with others in cyber space communication, where language is used as the principal medium. As there is no one correct way for the use of sarcasm and metaphor in ordinary dialogue, we calculated the MSST-A score for each respondent by extracting five answers where the selection rate by respondents was between 60 and 70 percent, and then 
summing up the raw scores for the five questions by granting one point to those who selected the most frequent answer and zero to those who selected other answers. The MSST-A score was applied to later calculations to develop a sarcasm and metaphor comprehension index. Table 3 shows the five MSSA-related questions for the comprehension of Internet terminology.

\subsection{Multiple regression analysis using problematic Internet experiences as dependent variables}

a) Multiple regression analysis using problematic Internet experiences as the dependent variables and the RMT synthesized factor scores as independent variables:

For each of the four problematic Internet experience categories classified through the exploratory factor analysis, a multiple regression analysis was conducted using the forced entry method, so as to show the degree of explanation ratio for the RMT synthesized factor scores as personal attributes. It was found that the standardized R2 $=.074$ (Pr. $=.000)$ for the item, "addiction tendency (to the Internet) (IT_1)" was significant. Of the personal attribute variables (RMT) entered for "addiction tendency," "avoidance of physical pain: RMTscr_5" ( $\beta=.193$, Pr. $=.000)$ and the "tendency to obey a person silently (according to an influence from the external environment): RMTscr_1" $(\beta=.124$, Pr. = .015) were found to be especially significant descriptive factors. The standardized $\mathrm{R} 2=.024$ (Pr. = .007) for "[dishonest/]illegal experiences (IT_2)" was also shown to be significant. Of the personal attribute variables (RMT) entered for "[dishonest/] illegal experiences," "sensation seeking tendency: RMTscr_2" ( $\beta=.128$, Pr. $=.015)$ was found to be an especially significant descriptive factor. The standardized R2 $=.041$ (Pr. = .000) for "communication (IT_3)" was found to be significant. For the personal attribute variables (RMT) entered for "communication," "sensation seeking tendency: RMTscr_2" ( $\beta=.138, \operatorname{Pr} .=.008)$ and the "desire to surpass existing regulations: RMTscr_4" ( $\beta=.013$, Pr. $=.049)$ were found to be especially significant descriptive factors. It was also found that the standardized R2 $=.028(\operatorname{Pr} .=.027)$ for "shopping (IT_4)" was significant. For the personal attribute variables (RMT) entered for "shopping," "desire to surpass existing regulations: RMTscr_4" ( $\beta=.20, \operatorname{Pr} .=.016)$ was found to be an especially significant descriptive factor. Although these factor values are low, we can see that there are Internet usage behavior patterns that could induce problems, as the different personal attribute factors suggested significant explicability for each problematic Internet experience (see Table 4). 
Yuhiko Toyoda, Mika Takeuchi, Hiroshi Ichikawa, Mitsuteru Tashiro, Masao Suzuki; Do Personal Attributes and An Understanding of Sarcasm and Metaphor Explain Problematic Experiences on the Internet? -A Survey for the Development of Information Literacy Education Tools-, Transactions on Networks and Communications, Volume 3 No 2, April (2015); pp: 159-177

Table 3 Metaphor and Sarcasm Scenario Test-for Adolescent (MSST-A) and the response rate of items applied to the Internet terminology comprehension scores ( $N=450)$

\begin{tabular}{|c|c|c|}
\hline MSST-A Question & Answer & $\%$ \\
\hline \multirow{6}{*}{$\begin{array}{l}\text { 30. When I eat all the snacks that are left } \\
\text { at home, my younger brother says, "You } \\
\text { have a good character." What does he } \\
\text { want to say? }\end{array}$} & 1 I think he praises my character. & $2.2 \%$ \\
\hline & 2 He says that I have eaten all the snacks. & $6.0 \%$ \\
\hline & 3 He is afraid if I will have a stomachache. & $0.2 \%$ \\
\hline & He wants to eat them too. & $21.6 \%$ \\
\hline & I should have left some for other people. & $65.6 \%$ \\
\hline & I do not know. & $4.7 \%$ \\
\hline \multirow{6}{*}{$\begin{array}{l}\text { 33. When I am putting in order clippings } \\
\text { featuring my favorite artist, my elder sister } \\
\text { says: "You are studying eagerly." What } \\
\text { does she want to say? }\end{array}$} & 1 She just says the fact that I am studying. & $16.7 \%$ \\
\hline & $\begin{array}{l}2 \text { She points out that I am eager for things I like although I } \\
\text { do not study other things. }\end{array}$ & $60.7 \%$ \\
\hline & 3 I think she is afraid if I will be tired. & $0.7 \%$ \\
\hline & $\begin{array}{l}4 \text { She says that because she also wants to be enthusiastic } \\
\text { about something. }\end{array}$ & $11.6 \%$ \\
\hline & 5 She says that I am doing "something good." & $5.6 \%$ \\
\hline & 6 I do not know. & $4.9 \%$ \\
\hline \multirow{6}{*}{$\begin{array}{l}\text { 38. I frame a tweet saying that I have } \\
\text { found a part-time job with high hourly pay } \\
\text { and my friend replies to me by saying } \\
\text { "Information kwsk (Internet slang for "tell } \\
\text { me more")." What is he thinking of? }\end{array}$} & 1 He thanks me for getting information about the job. & $12.4 \%$ \\
\hline & $\begin{array}{l}2 \text { He wants me to modify the wrong information that I } \\
\text { tweeted. }\end{array}$ & $0.4 \%$ \\
\hline & $\begin{array}{l}3 \text { He thinks that I do too much part-time job instead of doing } \\
\text { what I should do. }\end{array}$ & $0.4 \%$ \\
\hline & $4 \quad$ He is also interested in this job. & $69.6 \%$ \\
\hline & 5 His is not well paid for his job. & $0.2 \%$ \\
\hline & 6 I do not know. & $17.1 \%$ \\
\hline \multirow{6}{*}{$\begin{array}{l}\text { 42. On the occasion of a scandal involving } \\
\text { a politician, I check the related Internet } \\
\text { forum and find a contribution that a user } \\
\text { made saying "He will resign soon, } \\
\text { meshiuma (literally, "my meal will be } \\
\text { delicious!")." What is his/her feeling? }\end{array}$} & $1 \mathrm{He} /$ she feels sorry that the politician will resign. & $1.8 \%$ \\
\hline & $2 \mathrm{He} /$ she believes that politicians should behave correctly. & $7.8 \%$ \\
\hline & $3 \mathrm{He} /$ she is happy with someone else's unhappiness. & $69.1 \%$ \\
\hline & $4 \mathrm{He} / \mathrm{she}$ hopes that political reform will continue. & $3.3 \%$ \\
\hline & $\begin{array}{l}5 \text { The person who makes this comment knows that he/she is } \\
\text { having a good meal. }\end{array}$ & $1.3 \%$ \\
\hline & 6 I do not know. & $16.2 \%$ \\
\hline \multirow{6}{*}{$\begin{array}{l}\text { 43. When I make a proposition to hold a } \\
\text { voluntary study meeting as the lecture is } \\
\text { too difficult, my classmate says "Sore } \\
\text { Daretoku? (Who will benefit from this?)." } \\
\text { What is his/her feeling? }\end{array}$} & $1 \mathrm{He} / \mathrm{she}$ is disappointed that the lecture is too difficult. & $1.1 \%$ \\
\hline & $\begin{array}{l}2 \text { "It is too troublesome. It is rare for you to act goody-goody } \\
\text { like this." }\end{array}$ & $17.6 \%$ \\
\hline & $\begin{array}{l}3 \text { "I do not want to do troublesome things. This will be no } \\
\text { good for anyone." }\end{array}$ & $65.1 \%$ \\
\hline & $\begin{array}{l}4 \mathrm{He} / \text { she thinks that this is a useful proposition for } \\
\text { everyone. }\end{array}$ & $2.0 \%$ \\
\hline & $\begin{array}{l}5 \mathrm{He} / \text { she thinks that this will be a good opportunity for } \\
\text { him/her to achieve a good score. }\end{array}$ & $1.3 \%$ \\
\hline & $\begin{array}{ll}6 & \text { I do not know. } \\
\end{array}$ & $12.7 \%$ \\
\hline
\end{tabular}


Table 4 Multiple regression analysis using the total score for various problematic Internet experience factors (IT_1-IT_4) as the dependent variables and the RMT synthesized factor scores (RMTscr_1- RMTscr_5) as the independent variables (using the forced entry method)

\begin{tabular}{|c|c|c|c|c|}
\hline & $\begin{array}{l}\text { IT_1 Addiction } \\
\text { tendency } \\
\text { Standardized } \beta\end{array}$ & $\begin{array}{c}\text { IT_2 } \\
\text { Illegality experience } \\
\text { Standardized } \beta \\
\end{array}$ & $\begin{array}{c}\text { IT_3 } \\
\text { Communication } \\
\text { Standardized } \beta \\
\end{array}$ & $\begin{array}{c}\text { IT_4 Shopping } \\
\text { Standardized } \beta\end{array}$ \\
\hline $\begin{array}{l}\text { RMTscr_1 } \\
\text { Tendency to obey a } \\
\text { person silently }\end{array}$ & $.124(P r .=.015)$ & $.091(\operatorname{Pr} .=.079)$ & $.031(\operatorname{Pr} .=.552)$ & $.060(P r .=.900)$ \\
\hline $\begin{array}{l}\text { RMTscr_2 } \\
\text { Sensation seeking } \\
\text { tendency }\end{array}$ & $.061(P r .=.230)$ & $128(\operatorname{Pr} .=.015)$ & $.138(P r .=.008)$ & $.067(P r .=.252)$ \\
\hline $\begin{array}{l}\text { RMTscr_3 Anxiety } \\
\text { over relationship }\end{array}$ & $.060(\operatorname{Pr} .=.212)$ & $-.080(P r .=.106)$ & $.045(P r .=.359)$ & $-.119(P r .=.203)$ \\
\hline $\begin{array}{l}\text { RMTscr_4 Desire } \\
\text { to surpass } \\
\text { regulations } \\
\end{array}$ & $.056(\operatorname{Pr} .=.273)$ & $.025(\operatorname{Pr} .=.630)$ & $.103($ Pr. = .049) & $.020(P r .=.016)$ \\
\hline $\begin{array}{l}\text { RMTscr_5 } \\
\text { Avoidance of } \\
\text { physical pain }\end{array}$ & $.193(\mathrm{Pr} .=.000)$ & $.026(\operatorname{Pr} .=.592)$ & $.075(\operatorname{Pr} .=.124)$ & $.090(P r .=.703)$ \\
\hline$R^{2}$ & $.074(P r .=.000)$ & $.024(P r .=.007)$ & $.041(P r .=.000)$ & $.028(P r .=.027)$ \\
\hline
\end{tabular}

b) Multiple regression analysis using problematic Internet experiences as the dependent variables and level of familiarity with Internet terminology as the independent variables:

We wished to determine to what degree it was possible to predict the four kinds of problematic Internet experiences by focusing on specific Internet jargon. It was suggested that the use of such terms significantly predicted an "addiction tendency (IT_1)" as well as problematic experiences related to "communication (IT_3)."

It was found that the standardized R2 $=.104(\mathrm{Pr} .=.000)$ for "addiction tendency" was significant. Of the items related to the evaluation of familiarity with Internet terminology entered for "addiction tendency," "the jargon...wwww." (literally, "laugh, laugh, laugh, laugh"), showing rather scornful laughter about the object in question, was found to be an especially significant independent factor $(\beta=.197, \operatorname{Pr} .=.000)$. Moreover, for the problematic experiences in the category "communication IT_3," a weak but significant regression using the standardized R2 $=.034(\mathrm{Pr} .=.005)$ was observed, and especially in terms of terminology use, it was suggested that the word "godly," jargon which is frequently used to praise the interlocutor or others exaggeratedly, could explain problematic communication experiences $(\beta=.144, \operatorname{Pr} .=.029)$ (Table 5$)$. 
Yuhiko Toyoda, Mika Takeuchi, Hiroshi Ichikawa, Mitsuteru Tashiro, Masao Suzuki; Do Personal Attributes and An Understanding of Sarcasm and Metaphor Explain Problematic Experiences on the Internet? -A Survey for the Development of Information Literacy Education Tools-, Transactions on Networks and Communications, Volume 3 No 2, April (2015); pp: 159-177

Table 5 Multiple regression analysis using the total scores for various factors related to problematic Internet experiences (IT_1-IT_4) as the dependent variables and the level of familiarity with Internet terminology as the independent variables (using the forced entry method)

\begin{tabular}{|c|c|c|c|c|}
\hline & $\begin{array}{c}\text { IT_1 Addiction } \\
\text { tendency } \\
\text { Standardized } \beta\end{array}$ & $\begin{array}{c}\text { IT_2 } \\
\text { Illegal experience } \\
\text { Standardized } \beta\end{array}$ & $\begin{array}{c}\text { IT_3 Communication } \\
\text { Standardized } \beta\end{array}$ & $\begin{array}{lr}\text { IT_4 } & \text { Shopping } \\
\text { Standardized } \beta\end{array}$ \\
\hline W01A Godly & $.076(P r .=.231)$ & - & .144 (Pr. $=.029)$ & - \\
\hline $\begin{array}{l}\text { W02A kwsk (tell me } \\
\text { more) }\end{array}$ & $.090(P r .=.124)$ & - & $.088(\operatorname{Pr} .=.150)$ & - \\
\hline W03A Genius & $-.008(P r .=.892)$ & - & $-.003(P r .=.965)$ & - \\
\hline $\begin{array}{l}\text { W04A } \bigcirc \bigcirc \text { www } \\
\text { (scornful laughter) }\end{array}$ & $.197(P r .=.000)$ & - & $.075(P r .=.185)$ & - \\
\hline $\begin{array}{l}\text { W05A meshiuma } \\
\text { (literally, "my meal } \\
\text { will be delicious," } \\
\text { indicating the } \\
\text { sentiment of } \\
\text { schadenfreude) }\end{array}$ & $.021(P r .=.753)$ & - & $.065(P r .=.348)$ & - \\
\hline $\begin{array}{l}\text { W06A Sore daretoku? } \\
\text { (Who will benefit } \\
\text { from this?) }\end{array}$ & $-.062(P r .=.304)$ & - & $-.031(P r .=.625)$ & - \\
\hline $\begin{array}{l}\text { W07A orz } \\
\text { (disappointed) }\end{array}$ & $.108(P r .=.055)$ & - & $-.009($ Pr. $=.883)$ & - \\
\hline $\begin{array}{l}\text { W08A pgr (sentiment } \\
\text { of derision) }\end{array}$ & $-.037(\operatorname{Pr} .=.523)$ & - & $.019(P r .=.754)$ & - \\
\hline $\begin{array}{l}\text { W11A 888888 } \\
\text { (appraisal) }\end{array}$ & $.093(P r .=.088)$ & - & $-.038(P r .=.499)$ & - \\
\hline$R^{2}$ & $.104(P r .=.000)$ & n.s. & $.034(P r .=.005)$ & n.s. \\
\hline
\end{tabular}

c) Single regression analysis using problematic Internet experiences as the dependent variables and the MSSST-A and Internet terminology comprehension scores as the independent variables:

Here, we conducted a single regression analysis to determine to what degree the scores on the normal comprehension for sarcasm, metaphor and Internet terminology could explain the four problematic Internet experiences. It was found that factors that indicated a comprehension of sarcasm, metaphor and jargon significantly predicted "addiction dependency to the Internet, IT_1," "shopping, IT_4," and "communication, IT_3."

It was found that the standardized R2 $=.118$ (Pr. = .012) for "addiction tendency (IT_1)" was significant. For "addiction tendency," the values of $\beta=-.112$ and Pr. $=.017$ were obtained. The standardized R2 = .013 (Pr. = .017) for "shopping (IT_4)" was significant with the values of $\beta=-.112$ and Pr. $=.017$. For problematic experiences corresponding to "communication (IT_3)," the standardized R2 was not found to be a significant regression coefficient, but the reference value of $\beta$ $=.097$ and Pr. $=.040$ was suggested (Table 6).

Table 6 Single regression analysis using problematic Internet experiences as dependent variables and the MSST-A and Internet terminology comprehension scores as the independent variables (using the forced entry method)

\begin{tabular}{|c|c|c|c|c|}
\hline & $\begin{array}{l}\text { IT_1 Addiction } \\
\text { tendency } \\
\text { Standardized } \beta\end{array}$ & $\begin{array}{l}\text { IT_2 Illegal } \\
\text { experience } \\
\text { Standardized } \beta\end{array}$ & $\begin{array}{l}\text { IT_3 Communication } \\
\text { Standardized } \beta\end{array}$ & $\begin{array}{l}\text { IT_4 Shopping } \\
\text { Standardized } \beta\end{array}$ \\
\hline $\begin{array}{c}\text { Scores for MSST-A } \\
\text { and terminology } \\
\text { comprehension }\end{array}$ & $\mathbf{. 1 1 8 ( P r . = . 0 1 2 )}$ & - & $\mathbf{. 0 9 7}(\boldsymbol{P r} . \mathbf{= . 0 4 0 )}$ & $\mathbf{- . 1 1 2 ( P r . = . 0 1 7 )}$ \\
\hline$R^{2}$ & $\mathbf{. 0 1 2}(\boldsymbol{P r}, \mathbf{= . 0 1 2})$ & n.s. & n.s. & $\mathbf{. 0 1 3}(\boldsymbol{P r},=.017)$ \\
\hline
\end{tabular}




\subsection{Factors explaining the relationship between private Internet connection time and problematic Internet experiences}

A single regression analysis using Internet connection time as the independent variable did not significantly predict any of the problematic Internet experience categories. A simple correlation was calculated between the personal attributes RMTscr, which had been entered so far as independent variables, and the comprehension scores for sarcasm, metaphor and Internet terminology. Internet connection time was found to have a significant correlation with "addiction tendency (IT_1)" ( $r$ = .208 , Pr. $=.000$ ) and the "tendency to obey a person silently (according to an influence from the external environment)" $(r=.109$, Pr. $=.024)$, among other problematic Internet experience categories.

\section{Discussion and Conclusion}

At present, the Internet or "cyber space" is an information tool widely used in the social life of children, adolescents, and adults. Few people would deny that a virtual world "exists" in parallel with the real world. Those who have access to the network environment and who have accessibility recognize themselves as "residents" of both the real world and the cyber world. Studies on the developmental processes children go through to learn communication with others have so far assumed a simultaneous interaction with others in a face-to-face manner. Our survey data demonstrated that in the study of communication and cognitive development in such fields as psychology, it is necessary to pay attention to the role of "cyber space" in children's development.

Our survey data suggested several areas that should be included in information literacy education.

1) It has been proven that problematic Internet experiences can be roughly classified into addictive Internet access, tendency to engage in unlawful and illegal behavior, communication errors and misunderstanding, and problems with commercial transactions over the Internet.

2) The survey results suggested that people whose personal attributes make them open to fraud, unscrupulous business, and solicitation risks, have a tendency for collective behavior selection, which includes suggestibility and rising anxiety. Further, a tendency toward anxiety over relationships is because of a fear of hurting others' feelings. The desire for sensation-seeking, however, indicates an egocentric intention to ignore existing regulations, and a tendency to avoid physical activities in the real world.

3) For the comprehension of sarcasm, metaphor, and Internet terminology, we had difficulty developing questions and exercises that students would face in their actual daily life as they might be differently understood and interpreted (including within a communication context on the Internet). However, several questions allowed us to observe deviated samples with a response rate that could be used for a statistical test. It was confirmed that it is possible to predict problematic Internet experiences using sample groups that suggest differences in the understanding of such metaphor, sarcasm and Internet terminology. The "addiction tendency to the Internet, IT_1" and "shopping, IT_4" which were related to shopping experiences over the Internet suggested that scores on the comprehension of sarcasm, metaphor, and Internet terminology had weak but significant explanatory power.

4) Today, "Internet addiction" is an issue that has been recognized as posing a threat to adolescent psychological and social health. This is an addiction category that has received increasing attention over the last ten years in the fields of clinical and educational psychology and psychiatry. Based on the data obtained from this survey, the profile of "Internet addiction" as a problematic 
Yuhiko Toyoda, Mika Takeuchi, Hiroshi Ichikawa, Mitsuteru Tashiro, Masao Suzuki; Do Personal Attributes and An Understanding of Sarcasm and Metaphor Explain Problematic Experiences on the Internet? -A Survey for the Development of Information Literacy Education Tools-, Transactions on Networks and Communications, Volume 3 No 2, April (2015); pp: 159-177

behavior can be described in the following manner. Those who access the Internet addictively, while being also affected by suggestibility and anxiety, also sometimes post messages deriding others, including "...wwww." In general, they tend to choose collective swarm behavior and avoid physical activities (in the real world). It has also been suggested that some tend to select "deviated values" in the comprehension of sarcasm, metaphor, and Internet terminology. Urgent intervention measures are needed if pressure from collective society drives young people to spend more time connected to the Internet than they spend living and interacting with others in the real world.

5) It was also interesting that the "sensation-seeking tendency RMTscr_2," which is considered to be a personal attribute of social risk, was found to be significantly predictive of problems classified as belonging to the category "illegal experiences IT_2," including putting in danger one's personal information or the secrets of their organization. Curiosity and sensation-seeking (fear of boredom) are developmental issues for children and adolescents who extend their sphere of activity from their family to society. Many children and adolescents have the possibility of entering into dangerous worlds out of curiosity or sensation-seeking. This study suggested that this should be taken into consideration in information literacy education programs.

In Japan, high schools and universities deliver courses on information literacy and conduct lectures on Internet use. They teach young people, who are actual users, how to behave prudently, and they present comprehensive examples of potential problems. However, it is generally outside class time that young people access the Internet, which makes it difficult to know whether such information literacy education has any effect on improving their knowledge and self-management capacity.

To further reduce the risks related to Internet use, educational intervention aimed at promoting users' awareness of their personal behavioral characteristics and intentions should be provided. If students were aware of the risks they expose themselves to by going through a self-analysis process prior to Internet use, this may reduce their propensity for risky behavior.

This study was conducted on female students on the basis of self-reflection by the respondents. By performing surveys which target users of various ages, we could examine in more detail the factors related to the problems young people have when using the Internet as well as the personal characteristics of those who could be more likely to experience such problems.

In surveys based on self-report responses, there is a possibility that the problems encountered on the Internet might not be reflected unless the participants recognized these as problems. Further, the presence of samples where the responses were based on what the teacher wanted cannot be excluded due to the survey method used in this study. Nevertheless, differences between individuals as regards the understanding of "sarcasm," "metaphor," and "specific Internet terminology" and in the number of problems encountered were observed. This study has been valuable in that clues to the risk factors for "Internet problems" have been suggested.

In the future, it will become necessary to develop educational tools that could be used to estimate the risk of Internet use and to call attention in a more concrete and useful way to each individual's behavioral attributes by collecting more examples and additional survey data. It is necessary to establish information literacy education programs aimed at helping adolescents become aware of the necessity of protecting themselves and of achieving skills for safe Internet use.

This work was supported by JSPS Grant Number 25330429. 


\section{REFERENCES}

[1] OECD: THE PROTECTION OF CHILDREN ONLINE: Risks faced by children online and policies to protect themtal Psychology, 14, 19asses of Collective Attention in Twitter. In Proceedings of the 21st International Confere(accessed 2014-12-17)

[2] Ministry of Internal Affairs and Communications Institute for Information and Communications Policy. Announcement of Issuance of FY2013 Internet Literacy Indicator for Students Etc. http://www.soumu.go.jp/main_content/000175589.pdf（accessed 201412-17).

[3] HIRAI Tomohisa. (2012). Why does "Enjyo" happen on the Web? : An Examination based on Japanese Web Culture, Journal of Information and Communication Research, Vol.29 No.4, 61-71.

[4] Thurlow, C., Lengel, L., and Tomic, A. (2004). 004e .mic, 18101ification method of Internet related troubles, MT) as a new

[5] O'Sullivan, P.B. and Flanigan, A.J. (2003). Reconceptualizing 'Flaming' and Other Problematic Messages, New Media \& Society, Vol.5 (1): 69-94, SAGE.

[6] Takeichi, Y., Sasahara,K., Suzuki, R., and Arita,T. (2014). Twitter as Social Sensor: Dynamics and Structure in Major Sporting Events, Artificial Life 14, 778-784.

[7] Kwak, H., Lee, C., Park, H., and Moon, S. (2010). What is Twitter, a Social Network or a News Media? In Proceedings of the 19th International Conference on World Wide Web, 591-600.

[8] Bollen, J., Goncalves, B., Ruan, G., and Mao, H. (2011a). Happiness is Assortative in Online Social Networks. Artificial Life, 17(3):237-251.

[9] Gabowicz, P. A., Ramasco, J. J., Moro, E., Pujol, J. M., and Egu'ıluz, V. M. (2012). Social Features of Online Networks: The Strength of Intermediary Ties in Online Social Media.PLoS ONE, 7(1);e29358

[10] Conover, M. D., Gonc, alves, B., Flammini, A., and Menczer, F. (2012). Partisan Asymmetries in Online Political Activity. EPJ Data Science, 1(1):6.

[11] Romero, D. M., Meeder, B., and Kleinberg, J. (2011). Differencesyrne, \& Whiten, A. (Eds.), Machiavellian intelligence: Social expertise and the evolution of intellect in monkeys, apes, and humans. Oxford: Clarendoternational Conference on World Wide Web, 695-704.

[12] Weng, L., Flammini, A., Vespignani, A., and Menczer, F. (2012). Competition among memes in a world with limited attention. Scientific Reports, 2:335.

[13] Lehmann, J., Gonc,alves, B., Ramasco, J. J., and Cattuto, C. (2012). Dynamical Classes of Collective Attention in Twitter. In Proceedings of the 21st International Conference on World Wide Web, 251-260. 
Yuhiko Toyoda, Mika Takeuchi, Hiroshi Ichikawa, Mitsuteru Tashiro, Masao Suzuki; Do Personal Attributes and An Understanding of Sarcasm and Metaphor Explain Problematic Experiences on the Internet? - A Survey for the Development of Information Literacy Education Tools-, Transactions on Networks and Communications, Volume 3 No 2, April (2015); pp: 159-177

[14] Golder, S. A. and Macy, M.W. (2011). Diurnal and Seasonal Mood Vary with Work, Sleep, and Daylength Across Diverse Cultures. Science, 333(6051):1878-1881.

[15] Sakaki, T., Okazaki, M., and Matsuo, Y. (2010). Earthquake Shakes Twitter Users: Real-Time Event Detection by Social Sensors. In Proceedings of the 19th International Conference on World Wide Web, 851-860.

[16] Borge-Holthoefer, J., Rivero, A., Garc'ıa, I., Cauh'e, E., Ferrer, A., Ferrer, D., Francos, D., I niguez, D., P'erez, M. P., Ruiz, G., Sanz, F., Serrano, F., Vĩnas, C., Taranc'on, A., and Moreno, Y. (2011). Structural and Dynamical Patterns on Online Social Networks: The Spanish May 15th Movement as a Case Study. PLoS ONE, 6(8):e23883.

[17] Gonz' alez-Bail' on, S., Borge-Holthoefer, J., Rivero, A., and Moreno, Y. (2011). The Dynamics of Protest Recruitment through an Online Network. Scientific Reports, 1:197.

[18] Takahashi, T., Tomioka, R., and Yamanishi, K. (2014). Discovering Emerging Topics in Social Streams via Link-Anomaly Detection. Knowledge and Data Engineering, IEEE Transactions on, 26(1):120-130.

[19] Bollen, J., Mao, H., and Zeng, X. (2011b). Twitter Mood Predicts the Stock Market. Journal of Computational Science, 2(1):1-8.

[20] Sasahara, K., Hirata, Y., Toyoda, M., Kitsuregawa, M., and Aihara, K. (2013). Quantifying Collective Attention from Tweet Stream. PLoS ONE, 8(4):e61823.

[21] Heinrich, HW. 1931. Industrial Accident Prevention. New York: McGraw-Hill.

[22] Premack, D., \& Woodruff, G. (1978). Does the chimpanzee have a theory of mind? The Behavioral and Brain Sciences, 1, 515-526.

[23] Premack, D. (1988). 'Does the chimpanzee have a theory of mind?' revisited. In R. Byrne, \& Whiten, A. (Eds.), Machiavellian intelligence: Social expertise and the evolution of intellect in monkeys, apes, and humans. Oxford: Clarendon Press. 160-179.

[24] Hobson, R.P. (1993). Autism and the development of mind. Hove: Lawrence Erlbaum Associates.

[25] Moore, C. (1996). Theories of mind in infancy. British Journal of Developmental Psychology, 14, 19-40.

[26] Simon Baron-Cohen, Alan M. Leslie, Uta Frith. (1985). Does the autistic child have a "theory of mind" ?, Cognition, Volume 21, Issue 1, 37-46.

[27] Takamiya, Matsui et al (2009). Brain activation associated with theory of mind: An fMRI study. Journal of Human Environmental Studies Vol. 7 (2009) No. 2 P 129-135. 
[28] Moriguchi, Y. 2011 Psychosomatic medicine and neuroscience on understanding of selves and other's mind. Journal of the Human Arts and Sciences Vol. 7 (2011) No. 1 10-16.

[29] Adachi, T. (2006). The Study of Situational Recognition of Attention Deficit/Hyperactivity Disorders, Asperger's Disorder and High Functioning Autism with the Metaphor and Sarcasm Scenario Test (MSST), Official Journal of the Japanese Society of Child Neurology 38(3), 177-181, 2006-05-01.

[30] Takeuchi, M., Suzuki, M. (2000). The basic study of the Self Risk Management Test (SRMT) as a new tool for the educational programs informing lifetime risks of swindling victimization, Sanno College Junior Bulletin, Vol.33, 11-24.

[31] Maslow, A.H. (1954). Motivation and Personality, Harper \& Row, NY.

[32] Cloninger, C.R. (1987). A systematic method for clinical description and classification of personality varients: a proposal. Arch. Gen. Psychiat., 44, 573-588.

[33] Tashiro, M. (2011). Proposal of classification method of Internet related troubles, The Infosocionomics Society Vol.6, No.1, $101-114,2011-6-18$. 